\title{
PENERAPAN MODEL QUANTUM TEACHING DISERTAI TEKA-TEKI MATEMATIKA PADA PEMBELAJARAN MATEMATIKA SISWA KELAS VII SMP
}

\author{
Nia Rusni ${ }^{1}$, Yurnalis ${ }^{2}$ \\ Fakultas Keguruan dan Ilmu Pendidikan \\ Universitas Muhammadiyah Sumatera Barat \\ 1niarusni@gmail.com, ${ }^{2}$ ena_yurnalis@ymail.com
}

\begin{abstract}
Abstrac
Learning outcomes are the achievement of competencies that include aspects of knowledge, skills, attitudes, and values embodied in the habits of thinking and acting. Good learning outcomes indicate that learning has gone well. However, based on interviews conducted in class VII SMP Negeri 4 Padangpanjang shows that mathematics learning outcomes obtained by students are still far from satisfactory. This happens because learning has not been able to make students interested in learning. Efforts are being made to improve learning outcomes by applying the Quantum Teaching model accompanied by mathematical puzzles. So the research was conducted by applying the Quantum Teaching model accompanied by mathematical puzzles in mathematics learning in grade VII of SMP Negeri 4 Padangpanjang. This study aims to determine whether student learning outcomes in the cognitive domain in mathematics learning.

This type of research is an experiment, with a Randomized Control Group Only Design research design. The research population was Grade VII students of SMP Negeri 4 Padangpanjang in 2019/2020 Academic Year. Sampling is done by random sampling technique. The sample in this study was class VII 3 as an experimental class with 32 students and class VII 2 as a control class with 32 students. The research instrument used was the final test. Data analysis techniques in this thesis are learning outcomes in the cognitive domain of mathematics students.

Test data analysis was performed using t-test. Based on the results of data analysis at 95\% confidence level $(a=0,05)$ and degrees of freedom 70 , the price of $t_{\text {hitung }}=2.1917$ and $t_{(0,95 ; 62)}=1.6698$. Because the value of $t_{\text {hitung }}>t_{(0,95 ; 62)}$ means that $H_{0}$ is rejected and $H_{1}$ is accepted thus learning outcomes in the cognitive domain of students who follow the application of the Quantum Teaching model with mathematical puzzles are better than students who follow without the application of the Quantum Teaching model with mathematical puzzles in class VII SMP N 4 Padangpanjang in the 2019/2020 school year.
\end{abstract}

Keywords : Quantum Teaching and Puzzles.

\begin{abstract}
Abstrak
Hasil belajar merupakan pencapaian kompetensi yang mencakup aspek pengetahuan, keterampilan, sikap, dan nilai-nilai yang diwujudkan dalam kebiasaan berpikir dan bertindak. Hasil belajar yang baik menunjukkan bahwa pembelajaran telah berjalan dengan baik. Namun, berdasarkan wawancara yang dilakukan di kelas VII SMP Negeri 4 Padangpanjang menunjukkan bahwa hasil belajar matematika yang diperoleh siswa masih jauh dari memuaskan. Hal ini terjadi karena pembelajaran belum mampu membuat siswa tertarik untuk belajar. Upaya yang dilakukan untuk meningkatkan hasil belajar adalah dengan menerapkan model Quantum Teaching disertai teka-teki matematika. Sehingga diadakan penelitian dengan menerapkan model Quantum Teaching
\end{abstract}


disertai teka-teki matematika pada pembelajaran matematika di kelas VII SMP Negeri 4 Padangpanjang. Penelitian ini bertujuan untuk mengetahui apakah hasil belajar siswa pada ranah kognitif dalam pembelajaran matematika.

Jenis penelitian ini adalah eksperimen, dengan rancangan penelitian Randomized Control Group Only Design. Populasi penelitian adalah siswa kelas VII SMP Negeri 4 Padangpanjang Tahun Pelajaran 2019/2020. Pengambilan sampel dilakukan dengan teknik random sampling. Sampel dalam penelitian ini adalah kelas VII 3 sebagai kelas eksperimen dengan jumlah siswanya 32 orang dan kelas VII 2 sebagai kelas kontrol dengan jumlah siswanya 32 orang. Instrumen penelitian yang digunakan adalah tes akhir. Teknik analisis data dalam skripsi ini adalah hasil belajar pada ranah kognitif matematika siswa.

Analisis data tes dilakukan dengan menggunakan uji- t. Berdasarkan hasil analisis data pada taraf kepercayaan 95\% $(a=0,05)$ dan derajat kebebasan 70 diperoleh harga $t_{\text {hitung }}=2,1917$ dan $t_{(0,95 ; 62)}=1,6698$. Karena nilai $t_{\text {hitung }}>$ $t_{(0,95 ; 62)}$ berarti $H_{0}$ ditolak dan $H_{1}$ diterima dengan demikian hasil belajar pada ranah kognitif matematika siswa yang mengikuti penerapan model Quantum Teaching disertai teka-teki matematika lebih baik daripada siswa yang mengikuti tanpa penerapan model Quantum Teaching disertai teka-teki matematika pada kelas VII SMP N 4 Padangpanjang tahun pelajaran 2019/2020.

Kata Kunci : Quantum Teaching dan Teka-teki.

\section{PENDAHULUAN}

Pendidikan merupakan hal yang penting sebagai sarana untuk meningkatkan kualitas Sumber Daya Manusia (SDM) dan kelangsungan hidup bangsa. Menurut Undang-Undang Nomor 20 Tahun 2003 tentang Sistem Pendidikan Nasional, Pasal 1 ayat 1 menyatakan bahwa:

Pendidikan adalah usaha sadar dan terencana untuk mewujudkan suasana belajar dan proses pembelajaran agar siswa secara aktif mengembangkan potensi dirinya untuk memiliki kekuatan spiritual keagamaan, pengendalian diri, kepribadian, kecerdasan, akhlak mulia, serta keterampilan yang diperlukan dirinya, masyarakat, bangsa dan negara. Pendidikan merupakan asset penting bagi suatu bangsa termasuk bangsa Indonesia agar bisa lebih mengembangkan potensi masyarakat di dalamnya.

Pembelajaran merupakan proses yang dilakukan guru untuk mengembangkan pengetahuan, keterampilan dan sikap yang lebih baik pada saat individu berinteraksi dengan lingkungan. Undang-Undang Sistem Pendidikan Nasional No. 20 Tahun 2003 menyatakan bahwa "Pembelajaran adalah proses interaksi peserta didik dengan pendidik dan sumber belajar pada suatu lingkungan belajar". Oleh sebab itu, seorang guru selalu berusaha untuk menciptakan proses interaksi yang baik dengan para siswanya.

Tujuan pembelajaran matematika menurut Kurikulum 2013 (Kemendikbud, 2013) menekankan pada dimensi pedagogik modern dalam pembelajaran, yaitu menggunakan pendekatan scientific (ilmiah). Dalam pembelajaran matematika kegiatan yang dilakukan agar pembelajaran bermakna yaitu mengamati, menanya, mencoba, menalar, menyaji, dan mencipta.

Berdasarkan hasil wawancara yang peneliti lakukan pada tanggal 1 Oktober 2019 dengan salah satu guru bidang studi matematika, menunjukkan 
bahwa ada beberapa faktor yang menyebabkan rendahnya hasil belajar matematika siswa diantaranya cara belajar siswa masih bersifat monoton dan kurangnya minat dari dalam diri siswa saat proses pembelajaran berlangsung. Hal ini terlihat dalam proses pembelajaran yang umumnya dilakukan dengan diskusi kelompok sebagai tuntunan kurikulum 2013. Namun kenyataannya pada saat siswa melakukan diskusi kelompok, siswa cenderung kurang bersemangat dalam mendemonstrasikan hasil diskusi. Permasalahan ini disebabkan karena siswa kurang mampu menyelesaikan soal cerita yang umum diberikan pada saat diskusi berlangsung.

Pemberian soal cerita yang lebih dikaitkan pada kehidupan seharihari seharusnya lebih mudah diselesaikan, namun guru kurang dalam pengaplikasiannya. Sehingga siswa mudah lupa dan cenderung diam jika guru bertanya tentang materi yang diajarkan sebelumnya. Pada akhir pembelajaran guru masih jarang memberikan apresiasi setiap akhir pembelajaran. Apresiasi kepada siswa sebenarnya juga memiliki peran penting untuk meningkatkan semangat dan minat siswa dalam pembelajaran. Dengan memberikan penghargaan ini siswa merasa usaha yang telah dilakukan dihargai oleh guru dan teman-temannya. Secara tidak langsung siswa akan berlomba-lomba untuk memberikan penampilan terbaik dari kelompoknya dalam diskusi.

Untuk mengatasi masalah yang dihadapi siswa, perlu adanya tindakan yang tepat guna dalam memperbaiki proses pembelajaran sehingga diperoleh hasil pembelajaran yang diinginkan. Salah satu alternatif model pembelajaran yang cocok diterapkan untuk mengatasi masalah di atas adalah dengan model pembelajaran Quantum Teaching. Hal ini terjadi karena Quantum Teaching lebih melibatkan siswa secara langsung dan pembelajaran yang disajikan lebih menyenangkan. DePorter, Reardon dan Singer (2014: 32) menyatakan bahwa:

Quantum Teaching adalah penggubahan belajar yang meriah, dengan segala nuansanya. Dan Quantum Teaching juga menyertakan segala kaitan, interaksi, dan perbedaan yang memaksimalkan momen belajar. Quantum Teaching berfokus pada hubungan dinamis dalam lingkungan kelas-interaksi yang mendirikan landasan dan kerangka untuk belajar.

Model pembelajaran Quantum Teaching juga merupakan model yang mengubah cara belajar siswa menjadi meriah dengan segala paduan nuansanya. Pembelajaran diisi dengan kegembiraan yang membuat kegiatan belajar mengajar menjadi lebih menyenangkan. Kegembiraan membuat siswa siap untuk belajar dengan lebih baik dan dapat mengubah sikap negatif yang selama ini ditunjukkan oleh siswa. Namun tidak dapat dipungkiri bahwa kejenuhan belajar sering tiba-tiba terjadi pada siswa.

Untuk menghindari timbulnya kejenuhan pada siswa, diperlukan sedikit jeda selama proses belajar mengajar berlangsung. Hal ini juga dapat memaksimalkan penerapan model Quantum Teaching DePorter dan Hernacki (2001: 240) juga mengatakan bahwa "Ambillah jeda sesering mungkin ketika mempelajari atau mengulang sesuatu yang panjang". Jeda dirasa perlu untuk memberikan istirahat sejenak kepada otak, dan 
memberikan waktu untuk memaksimalkan kemampuan menyimpan informasi.

Adapun rumusan masalah dalam penelitian ini adalah Apakah hasil belajar siswa pada ranah kognitif dalam pembelajaran matematika dengan menggunakan model Quantum Teaching disertai teka - teki matematika lebih baik daripada hasil belajar siswa pada ranah kognitif dalam pembelajaran matematika tanpa menggunakan model Quantum Teaching disertai teka - teki matematika pada kelas VII SMP N 4 Padangpanjang tahun pelajaran 2019/2020.

Berdasarkan rumusan masalah, maka penelitian ini bertujuan untuk mengetahui hasil belajar siswa pada ranah kognitif dalam pembelajaran matematika dengan menggunakan model Quantum Teaching disertai teka teki matematika pada kelas VII lebih baik daripada hasil belajar kognitif tanpa menggunakan model Quantum Teaching disertai teka - teki matematika pada kelas VII SMP N 4 Padangpanjang tahun pelajaran 2019/2020.

Hipotesis dalam penelitian ini adalah Hasil belajar siswa pada ranah kognitif dalam pembelajaran matematika dengan menggunakan model Quantum Teaching disertai teka-teki matematika lebih baik daripada hasil belajar siswa pada ranah kognitif dalam pembelajaran matematika tanpa menggunakan model Quantum Teaching disertai teka-teki matematika pada kelas VII SMP N 4 Padangpanjang tahun pelajaran 2019/2020.

\section{METODOLOGI PENELITIAN}

Penelitian ini adalah penelitian eksperimen. Penelitian eksperimen ini bertujuan untuk mengetahui ada tidaknya suatu akibat yang ditimbulkan terhadap suatu objek yang diberikan perlakuan tertentu. Rancangan yang digunakan dalam penelitian ini adalah Randomized Control Group Only Design yaitu sekelompok subjek yang diambil dari populasi tertentu dikelompokkan secara rambang menjadi dua kelompok yaitu kelompok eksperimen dan kelompok kontrol. Setelah itu kedua kelompok itu dikenai pengukuran yang sama. Perbedaan yang ditimbul dianggap bersumber pada variabel perlakuan (Suryabrata, 2012:104).

Arikunto (2006:130) menyatakan bahwa "Populasi adalah keseluruhan subjek penelitian". Populasi dalam penelitian ini adalah siswa kelas VII SMP Negeri 4 Padangpanjang yang terdaftar pada tahun pelajaran 2019/2020 yang terdiri dari lima kelas. Pengambilan sampel dengan menggunakan Random Sampling. Sampel dalam penelitian ini adalah kelas VII 3 sebagai kelas eksperimen dengan jumlah siswanya 32 orang dan kelas VII 2 sebagai kelas kontrol dengan jumlah siswanya 32 orang.

Menurut (Arikunto,2006:118) "Variabel adalah objek penelitian atau apa yang menjadi titik perhatian suatu penelitian.Variabel dalam penelitian ini adalah hasil belajar pada ranah kognitif pada kelas eksperimen dan kelas kontrol. Data yang digunakan dalam penelitian ini data primer dan data sekunder. Data primer yaitu data yang diambil secara langsung dari sampel melalui tes hasil belajar. Data sekunder, yaitu data tentang jumlah siswa yang menjadi populasi dan nilai ulangan harian siswa.

Prosedur penelitian dibagi menjadi 3 tahap, yaitu tahap persiapan, tahap pelaksanaan, dan tahap akhir. Instrumen yang digunakan adalah tes 
akhir. Instrumen tes akhir dikembangkan melalui uji coba soal dan validasi. Materi yang diujikan dalam tes adalah materi yang diberikan selama penelitian. Tes yang diujikan adalah tes tertulis dalam bentuk essay.

Pada teknik analisis data, dilakukan terlebih dahulu uji normalitas, diperoleh bahwa $\mathrm{L}_{\mathrm{o}}=0,1389, \mathrm{~L}_{(32 ; 0.05)}=0,1566$. Jadi, $\mathrm{L}_{\mathrm{o}}<\mathrm{L}_{\text {tabel }}$ untuk kelas eksperimen berarti data berdistribusi normal, dan kelas kontrol didapat $\mathrm{L}_{\mathrm{o}}=$ $0,1078, \mathrm{~L}_{(32 ; 0,05)}=0,1566$. Jadi, $\mathrm{L}_{\mathrm{o}}<\mathrm{L}_{\text {tabel }}$ berarti data berdistribusi normal. Setelah dilakukan uji normalitas, langkah selanjutnya melakukan uji homogenitas yang bertujuan untuk melihat apakah data yang berasal dari kedua sampel mempunyai variansi homogen atau tidak. Setelah dilakukan analisis terhadap hasil tes akhir siswa, didapatkan bahwa $x^{2}$ hitung $=0,5073$, $x_{(0,05) ;(4)}^{2}=3,841$. Jadi, $x_{\text {hitung }}^{2}<x^{2}{ }_{(0,05) ;(4)}$ sehingga $H_{o}$ diterima, yang berarti kedua kelompok data homogen pada tingkat kepercayaan $95 \%$. Setelah dilakukan analisis data berdistribusi normal dan homogen maka digunakan uji t. Berdasarkan hasil analisis data pada taraf kepercayaan $95 \%$ $(\alpha=0,05)$ dan derajat kebebasan 62 diperoleh harga $t_{\text {hitung }}=$ 2,1917 dan $t_{(0,95 ; 62)}=1,6698$. Karena nilai $t_{\text {hitung }}>t_{(0,95 ; 62)}$ berarti $\mathrm{H}_{0}$ ditolak atau $\mathrm{H}_{1}$ diterima dengan demikian Hasil belajar matematika siswa yang mengikuti penerapan model Quantum Teaching disertai teka - teki matematika lebih baik daripada hasil belajar matematika siswa yang tidak mengikuti penerapan model Quantum Teaching disertai teka - teki matematika pada kelas VII SMP N 4 Padangpanjang tahun pelajaran 2019/2020.

\section{HASIL PENELITIAN DAN PEMBAHASAN}

\section{Deskripsi data}

a. Hasil belajar matematika siswa pada ranah kognitif

Berdasarkan hasil belajar matematika pada ranah kognitif diperoleh nilai rata - rata $(\bar{x})$, nilai tertinggi $\left(x_{\text {maks }}\right)$, nilai terendah $\left(x_{\text {min }}\right)$, persentase ketuntusan dari kedua kelas sampel. Dari perhitungan tersebut dapat dilihat pada tabel 4.1.

Tabel 4.1 Data Hasil Belajar Siswa Pada Ranah Kognitif

\begin{tabular}{|c|c|c|c|c|c|}
\hline Kelas & $\mathbf{N}$ & $(\overline{\boldsymbol{x}})$ & $\boldsymbol{x}_{\text {maks }}$ & $\boldsymbol{x}_{\min }$ & \% Ketuntasan \\
\hline Eksperimen & 32 & 66,59 & 95 & 40 & 50 \\
\hline Kontrol & 32 & 57,56 & 87 & 30 & 25 \\
\hline
\end{tabular}

Sumber : Olahan data perhitungan tes akhir

Berdasarkan tabel 4.1 dapat dilihat bahwa siswa yang mendapatkan nilai tertinggi pada kelas eksperimen adalah 95 dan nilai terendahnya 40 . Dengan rata-rata nilai 66,59 dan persentase ketuntasan sebesar 50\%, dimana sebanyak 16 dari 32 orang siswa dinyatakan tuntas. tampak bahwa nilai rata - rata hasil belajar pada kelas eksperimen lebih tinggi daripada kelas kontrol.

\section{Uji hipotesis}

Setelah dilakukan uji homogenitas dan uji normalitas diketahui bahwa kedua kelompok data mempunyai variansi yang homogen dan berasal dari populasi yang berdistribusi normal, maka untuk menguji hipotesis dilakukan dengan menggunakan uji-t. 
Berdasarkan perhitungan didapatkan bahwa $t_{\text {hitung }}=2,1917$ dan $t_{\text {tabel }}=t_{\left(1-\alpha ; d_{f}\right)}=t_{(0,95 ; 62)}=1,6698$. Jadi $t_{\text {hitung }}>t_{\text {tabel }}$ maka $\mathrm{H}_{0}$ ditolak atau $\mathrm{H}_{1}$ diterima yaitu hasil belajar siswa pada ranah kognitif dalam pembelajaran matematika dengan menggunakan model Quantum Teaching disertai teka-teki matematika lebih baik daripada hasil belajar siswa pada ranah kognitif dalam pembelajaran matematika tanpa menggunakan model Quantum Teaching disertai teka-teki matematika pada kelas VII SMP $\quad \mathrm{N} 4$ Padangpanjang tahun pelajaran 2019/2020.

\section{Kendala yang dihadapi}

Pada saat melaksanakan pembelajaran dengan penerapan model Quantum Teaching disertai teka-teki matematika terdapat kendala yang dihadapi. Ada beberapa kendala diantaranya adalah masalah waktu. Ketika waktu pelajaran habis dan masih ada beberapa kelompok yang belum siap mempresentasikan hasil diskusi kelompoknya. Kendala kedua yaitu saat pembelajaran berlangsung ada beberapa siswa yang tidak serius saat pembelajaran berlangsung dan ada yang tidak serius saat melakukan diskusi sehingga ada yang mengganggu temannya. Selain itu, pada saat presentasi kelompok masih ada beberapa siswa yang meribut.

Untuk menghadapi masalah ini, peneliti memberikan motivasi kepada siswa yaitu dengan memberikan arahan serta bimbingan bagaimana cara belajar yang baik dan cara memperoleh hasil belajar yang memuaskan.

\section{KESIMPULAN}

Berdasarkan hasil penelitian dan pembahasan dapat disimpulkan bahwa hasil belajar siswa pada ranah kognitif dalam pembelajaran matematika dengan menggunakan model Quantum Teaching disertai teka-teki Matematika lebih baik daripada hasil belajar siswa pada ranah kognitif dalam pembelajaran matematika tanpa menggunakan model Quantum Teaching disertai teka-teki Matematika pada kelas VII SMP N 4 Padangpanjang.

\section{SARAN}

Berdasarkan hasil penelitian yang diperoleh, maka peneliti berharap:

1. Guru matematika, khususnya guru matematika kelas VII SMP N 4 Padangpanjang dapat menerapkan model Quantum Teaching disertai tekateki Matematika dalam proses pembelajaran sebagai cara alternatif untuk meningkatkan hasil belajar siswa.

2. Untuk pembaca, semoga bisa menambah ilmu pengetahuan dan wawasan.

3. Diharapkan adanya penelitian lanjutan dalam ruang lingkup yang lebih luas.

\section{DAFTAR KEPUSTAKAAN}

Arikunto, Suharsimi. 2006. Prosedur Penelitian Suatu Pendekatan Praktik. Jakarta: PT. Rineke Cipta

DePorter, Bobbi \& Hernacki, Mike. 2001. Quantum Learning: Membiasakan Belajar Nyaman dan Menyenangkan, a.b Alwiyah Abdurrahman. Bandung:Kaifa. 
DePorter,Bobbi.,Reardon, Mark., \& Singer-Nouri,Sarah.2014. Quantum Teaching: Mempraktikkan Quantum Learning di Ruang-Ruang Kelas, Terjemahan Ary Nilandari. Bandung: Kaifa.

Suryabrata, Sumadi. 2012. Metodologi Penelitian. Jakarta: Raja Grafindo Persada. 